\title{
Preparation of cellulose nanofibrils (CNF) with uniform diameter distribution from okara by ultrasonic and high-speed stirring treatment method using deep eutectic solvent
}

Peiyi Li ( $\sim$ lipeiyi@sust.edu.cn )

Shaanxi University of Science and Technology https://orcid.org/0000-0002-0233-6814

Haozhe Lei

College of Bioresources Chemical and Materials Engineering,Shaanxi University of Science \&amp; Technology, Xi'an, 710021, China

\section{Yumeng Wang}

College of Bioresources Chemical and Materials Engineering,Shaanxi University of Science \&amp; Technology, Xi'an 710021, China

Hezhen Liu

College of Bioresources Chemical and Materials Engineering, Shaanxi University of Science \&amp; Technology, Xi'an 710021, China

\section{Boxing Jian}

College of Bioresources Chemical and Materials Engineering, Shaanxi University of Science \&amp; Technology, Xi'an 710021, China

\section{Ruiyan Liu}

College of Bioresources Chemical and Materials Engineering, Shaanxi University of Science \&amp; Technology, Xi'an 710021, China

\section{Xinping Li}

College of Bioresources Chemical and Materials Engineering, Shaanxi University of Science \&amp; Technology, Xi'an 710021, China

\section{Research Article}

Keywords: Okara, Deep eutectic solvent (DES), Cellulose nanofibrils (CNF), High Speed-Stirring, High pressure homogenization, recovery

Posted Date: February 16th, 2021

DOl: https://doi.org/10.21203/rs.3.rs-183818/v1 
License: (c) (i) This work is licensed under a Creative Commons Attribution 4.0 International License. Read Full License 


\section{Abstract}

Cellulose nanofibrils (CNF) is a nanomaterial with excellent performance. It is an important issue to control the CNF diameter during its preparation. In this study, a green and environmentally friendly method for rapid CNF preparation with great cost advantage is reported. Deep eutectic solvent (DES) and different mechanical treatment methods were used to obtain CNF with different diameter distribution. The results showed that ultrasonic treatment resulted in CNF with a uniform diameter distribution of 28 $\mathrm{nm}$ and high-speed stirring treatment resulted in CNF with a uniform diameter distribution of $27 \mathrm{~nm}$. The method of using high-speed stirring to prepare CNF has great energy consumption advantages compared with traditional high-pressure homogenization methods. The yield of okara CNF before and after DES treatment is not much different. The recovery rate of DES achieved more than $90 \%$ and demonstrated excellent treatment effect indicating DES-pretreatment for okara CNF preparation is economical, convenient and effective.

\section{Introduction}

With the depletion of the non-renewable petroleum resources, the development of high-value biological sustainable resources is imminent. Natural cellulose contained in various types of plants is the most abundant, sustainable and most widely distributed biological resource in nature. Nanocellulose or cellulose nanoparticles are cellulose elements with at least one dimension less than $100 \mathrm{~nm}$ (Isogai et al. 2011). In recent years, cellulose nanofibrils (CNF) or cellulose nanocrystals (CNC) have been widely used in pharmaceutical, biomedicine, electronic devices and polymer nanocomposites reinforcement materials(Thomas et al. 2018) due to its unique characteristics such as large surface area, high modulus, highly porous structures and biodegradability(Klemm et al. 2011).

CNF can be separated from a variety of cellulose sources including bleached kraft pulp, bleached sulfite pulp, bamboo pulp, balloonflower residue, straw, wheat straw, cocoa pods shell, bagasse, beet pulp, corn cob and Japanese cedar(Liu et al. 2016). Previous study showed, though the microfibrillation degree proportionally increased with the number of homogenization steps and gradually decreased after reaching a certain threshold, the performance of the resulted CNF remains constant(Li et al. 2020). In addition, raw banana, pineapple leaf fiber, flax, hemp, jute, and sisal and abaca leaf bast were also used to produce CNF(Chávez-Guerrero et al. 2019). Although wood is the main raw material for CNF production, industrial and agricultural wastes have been attracted great attention in recent years and used as an alternative fiber source for CNF preparation due to their abundance, low cost and renewable characteristics(Nechyporchuk et al. 2016).

Nowadays, China is one of the major soybean processing countries in the world(Li et al. 2018). As the world's major food and oil crops, soybeans processing for protein, soy flour, tofu produces a large amount of by-products called okara(Nsor-Atindana et al. 2019; Vong et al. 2017). Okara is a biomass resource rich in nutrients and its main components include dietary fiber (60\% - 70\%), protein (13\% - 20\%), fat (6\% $19 \%)$, lignin ( $\approx 1 \%)$, and ash (3.5\% - 5\%)(Mateos-Aparicio et al. 2010a; Mateos-Aparicio et al. 2010b). 
Furthermore $\rrbracket$ most okara is burned as waste or used as animal feed in Asian countries(Nagano et al. 2020). It also contains a small amount of soybean isoflavones, vitamins, soybean saponins, phytic acid, minerals and other substances(Li et al. 2012; Stanojevic et al. 2013). Okara is derived from the cotyledons of soybeans. The cotyledons are the vegetative tissues of soybeans and are also called parenchyma since they are composed of parenchyma cells. The fine fibers of parenchyma cells existing in the primary wall are loosely arranged and have a small binding force between each other and make it easy to be separated for CNF preparation(Peiyi et al. 2019). The traditional method for CNF preparation is to remove the lignin from the raw materials by acid and alkali process followed by mechanical treatment(Benini et al. 2018; llyas et al. 2017). The process is not conducive to lignin and chemical recovery and requires a lot energy, which does not follow the current green manufacturing practice and meet the environmental protection requirements.

DES synthesized by reaction of two or more monomer coordination substances which has a melting point much lower than either of the individual components is considered as green solvent(Paiva et al. 2014). The use of low melting point DES for okara CNF preparation can effectively reduce its impact on the structural properties of okara CNF(Bubalo et al. 2016). The used eutectic liquid can be effectively recycled and reused which can significantly reduce the production cost and the environment burden(Sirviö et al. 2018).

At present, high-pressure homogenization is the most commonly used method for CNF preparation(Wang et al. 2019). However, the method is not conducive to large-scale production because of the high energy requirement(Li et al. 2019). In this context, we investigated the use of DES for okara cellulose pretreatment and compared the performance of different mechanical dissociation methods for CNF production. We found that the dissociation method using ultrasound and high speed stirring produced CNF with uniform diameter distribution. Compared to high-pressure homogenization method, mechanical stirring showed greater energy consumption advantage and provided a new avenue for CNF preparation. We found that the recovery rate of DES reached more than $90 \%$ within three times of recovery and no diminished treatment efficiency was observed. This research provides a green, environmentally friendly and low energy consumption method for CNF preparation from okara by ultrasonic and high-speed stirring treatment method using deep eutectic solvent.

\section{Materials And Methods}

\section{1هMaterials}

Okara was obtained from a soy milk factory in Heilongjiang Province, China. Choline chloride $\left(\mathrm{C}_{5} \mathrm{H}_{14} \mathrm{ClNO}\right)$ was purchased from Adamas Beta (Shanghai) Chemical Reagent Co., Ltd. Oxalic acid $\left(\mathrm{C}_{2} \mathrm{H}_{2} \mathrm{O}_{4} 2 \mathrm{H}_{2} \mathrm{O}\right)$ was purchased from Tianjin Zhiyuan Chemical Reagent Co., Ltd. All chemicals are analytical grade and used without further purification.

\section{2ロPre-treatment of Okara cellulose using DES}


The eutectic solvent was prepared by mixing choline chloride and oxalic acid in a $100 \mathrm{ml}$ round bottom flask at a molar ratio of $1: 1$. The reaction was conducted at a constant temperature of $80^{\circ} \mathrm{C}$ under continuous magnetic stirring until the solution turned clear and transparent. The resulted DES was then used to treat the okara. Okara and DES were mixed in a conical flask at a ratio of 1:20. The reaction was carried out at $100{ }^{\circ} \mathrm{C}$ for $30-100$ min with a stirring speed of $40 \mathrm{r} / \mathrm{min}$. At the end of the experiment, reverse phase solvent - distilled water was used to precipitate the cellulose. The solid substrate was washed by distilled water until the filtrate became neutral. The collected cellulose was made into 2 wt $\%$ suspension using distilled water.

\section{3区High Pressure Homogenization Treatment}

$2 \%$ cellulose suspension was homogenized for 15 times using a high-pressure homogenizer under a pressure of $60 \mathrm{MPa}$.

\section{4区High Speed Stirring Treatment}

$2 \%$ cellulose suspension was poured into a high-speed mixer and processed for 3 minutes at a speed of $6000 \mathrm{r} / \mathrm{min}$.

\section{5区Ultrasonic Treatment}

$2 \%$ cellulose suspension was dissociated for 5 minutes using the cell shredder (JY92-IIDN, Ningbo Xinzhi Biological Technology Co. Ltd., China) at a ultrasonic frequency of $25 \mathrm{KHz}$ and output power of $800 \mathrm{~W}$. All samples were then freeze-dried at $-47^{\circ} \mathrm{C}$ for $12-24 \mathrm{~h}$.

\section{6هRecovery of DES from the spent liquor}

The recovery of DES was carried out by vacuum distillation. The distillation temperature was set at $60^{\circ} \mathrm{C}$ and the rotation speed was $80 \mathrm{r} / \mathrm{min}$.

\section{7凶Characterizations}

\subsection{1凶Scanning Electron Microscopy (SEM) Analysis}

SEM (S-4800, Hitachi, Tokyo, Japan) was used to visualize the structure of various CNFs. The SEM images were recorded at a low voltage of $5 \mathrm{kV}$ and a working distance of $5 \mathrm{~mm}$. The CNFs were affixed to metal stubs using double-faced tape and then coated with platinum by ion sputter instrument. The diameter of CNF was analyzed using Nano Measurer software (Department of Chemistry, Fudan University, Shanghai, China).

\subsection{2ХRecovery rate of DES and yield of cellulose}

The recovery rate of DES was defined as ratio of the amount of DES recovered from the spend liquor to its original amount used for okara treatment. The yield (\%) of cellulose extract by recycled DES was 
determined with $\mathrm{Eq}(1)$ :

Yield $(\%)=\frac{\left(M_{2}-M_{3}\right)}{M_{1}} \times 100 \%$

\subsection{3区Fourier Transform Infrared Spectroscopy (FTIR)}

Fourier transform infrared spectroscopy (FTIR) (Vertex, Brock, Germany) was used to identify the structure changes in okara nanocellulose. The dried okara celluloses were mixed with $\mathrm{KBr}$ at a ratio of 1:100 and was then thoroughly grounded in an agate grinder. Certain amount of the mixture was tableted at a pressure of $10 \mathrm{MPa}$ for $2 \mathrm{~min}$. The tablets were placed in an infrared spectrometer and scanned for 40 times from $500 \mathrm{~cm}-1$ to $4000 \mathrm{~cm}-1$ at a wave number resolution of $1 \mathrm{~cm}-1$.

\section{Results And Discussion}

\section{1区Effect of high pressure homogenization on CNF morphology and diameter distribution}

Figure 1 shows the morphology and diameter distribution of okara CNF prepared by high pressure homogenization. As a conventional mechanical treatment method, high-pressure homogenization is usually used to mechanically dissociate the okara fibers. During the dissociation process, okara fibers are gradually converted to CNF. However, the mechanical energy consumption during high-pressure homogenization is very large and the machine is prone to blockage which would negatively affects the CNF yield. During the high-pressure homogenization process, the pressure is continuously increased to 60 $\mathrm{MPa}$ to increase the mechanical shear force on okara fiber to achieve fully okara cellulose nanofibrillation. In the previous research, the morphology of the prepared okara CNF by the times of highpressure homogenization was discussed in detail. The results showed that 15 times high-pressure homogenization was the optimum homogenization condition. The diameter distribution of CNF prepared from less than 15 times high-pressure homogenization was not uniform and no obvious difference between the CNF obtained from more than 15 times high-pressure homogenization.

It can be seen from Fig. 1 that the diameter distribution of CNF prepared by high-pressure homogenization varies from $5 \mathrm{~nm}$ to $45 \mathrm{~nm}$ (relatively concentrated in the size range of $25-30 \mathrm{~nm}$ ) with an average diameter of $30 \pm 14 \mathrm{~nm}$.

\section{2区Effect of ultrasonic treatment time on CNF morphology and diameter distribution}

Ultrasonic treatment was used to mechanically dissociate the $2 \%$ cellulose to prepare okara CNF. The effect of treatment time on morphology and diameter distribution of CNF was investigated and the result is shown in Fig. 2. Less than 5 minutes ultrasonic treatment was not enough to completely dissociate cellulose. More than 5 minutes ultrasonic treatment consumed more energy but no difference was observed in CNF diameter and morphology. Thus, 5 minutes was determined as the optimum ultrasonic treatment time. 
The diameter of CNF obtained by 5 minutes ultrasonic treatment was 6 - $50 \mathrm{~nm}$ and had more uniform diameter distribution than those obtained from high-pressure homogenization. Compared to highpressure homogenization, ultrasonic dissociation process required less mechanical energy and the loss of the sample is small. Moreover, the operation of ultrasonic treatment is simple and the ultrasonic treatment can evenly disperse the suspension. The average diameter of CNF obtained by 5 minutes ultrasonic treatment was $28 \pm 9 \mathrm{~nm}$.

\section{3区Effect of high-speed stirring speed and mixing time on CNF morphology and diameter distribution}

High-pressure homogenization, ultrasonic treatment and high-speed stirring are the three most commonly used mechanical dissociation methods for CNF preparation. High-pressure homogenization requires the most and high-speed stirring requires the least energy input. Previous research showed high-speed stirring treatment can fully dissociated the cellulose sample and results in uniformly dispersed suspension(Li et al. 2020). It is thus necessary to evaluate the high-speed stirring speed and time on its efficiency and effectiveness for CNF preparation.

\section{Table 1 effect of stirring speed and mixing time on CNF diameter prepared by high speed stirring}

\begin{tabular}{ccc}
\hline Stirring speed / $\mathrm{r} \cdot$ min-1 & Mixing time / min & Average diameter / $\mathrm{nm}$ \\
\hline 3000 & 3 & 44 \\
& 6 & 27 \\
6000 & 3 & 27 \\
& 6 & 26 \\
\hline
\end{tabular}

Single-factor experiment was carried out to determine the effect of stirring speed and mixing time on the average diameter of the produced CNF. Table 1 shows the results. From the observation of the sample's macroscopic morphology during the experiment, different degrees of dispersion was observed at different stirring times. Less than 3 minutes high speed stirring was not enough to fully disintegrate the cellulose and some granular lumps were still observed. As shown in Table 1, when the stirring speed was set at $3000 \mathrm{r} / \mathrm{min}$, the average diameter of the CNF decreased from $44 \mathrm{~nm}$ to $27 \mathrm{~nm}$ with the increase of the stirring time from 3 minutes to 6 minutes. The increase of the stirring time did not significantly change the average diameter of CNF when the stirring speed was set at $6000 \mathrm{r} / \mathrm{min}$. When the stirring time was extended to 6 minutes, both stirring speed resulted in similar CNF diameter at about $27 \mathrm{~nm}$. Therefore, the CNF preparation through high speed stirring was conducted at $6000 \mathrm{r} / \mathrm{min}$ and 6 minutes.

Fig. 3 shows the morphology and diameter distribution of okara CNF prepared by high-speed stirring. The CNF prepared by high-speed stirring had an average diameter of $27 \pm 2 \mathrm{~nm}$.

In summary, three different mechanical methods were used for okara cellulose treatment, namely, highpressure homogenization, ultrasonic treatment and high-speed stirring. Nano Measurer software were used to analyze the above SEM to obtain the corresponding size distribution at different mechanical 
dissociation conditions. Then the properties of the CNF can be controlled for different applications by adjusting the mechanical treatment parameters.

Table 2 Control of CNF diameter by adjusting mechanical treatment parameters

$\begin{array}{lcccccc}\text { Mechanical } & \text { Speed / } & \text { Pressure } & \text { Frequency/Khz } & \text { Time } & \text { Average } & \text { Power } \\ \text { dissociation } & \mathrm{r} \cdot \mathrm{min}-1 & / \mathrm{MPa} & & \text { / } & \text { diameter / consumption/W }\end{array}$

\begin{tabular}{|c|c|c|c|c|c|}
\hline $\begin{array}{l}\text { High pressure } \\
\text { homogenization }\end{array}$ & & 60 & & 15 & $30 \pm 14$ \\
\hline Ultrasonic & & - & 25 & 5 & $28 \pm 9$ \\
\hline $\begin{array}{l}\text { High speed } \\
\text { stirring }\end{array}$ & 6000 & - & & 3 & $27 \pm 2$ \\
\hline
\end{tabular}

Table 2 shows the CNF diameter distribution at different experimental conditions for each mechanical treatment method. As seen from Table 2, high speed stirring consumed much less energy to produce CNF compared to the other two mechanical treatment methods.

Figure 4 shows the size distribution of CNF prepared by different mechanical dissociation methods. CNF can be prepared combining DES pretreatment to extract okara cellulose and different mechanical treatment. The diameter distribution is relatively wide, ranging from $5 \mathrm{~nm}$ to $50 \mathrm{~nm}$. Sum up, ultrasonic treatment and high-speed stirring can obtain uniform CNF size distribution which provides new inspiration for the application of CNF.

\section{4区FTIR analysis of the recycled DES}

Rotary evaporation was used to recover the DES after its treatment of okara cellulose. The recovered DES was characterized by infrared spectroscopy.

The infrared spectrum of DES as shown in Fig. 5 shows the following typical peaks. $3272 \mathrm{~cm}^{-1}$ is a nonlinear tensile vibration peak. The two absorption peaks of $\mathrm{CN}$ and $\mathrm{CH}$ bending vibration are located at the front end of $3018 \mathrm{~cm}^{-1}$, while the tensile vibration of $\mathrm{CO}$ and $\mathrm{CN}$ is placed at $1637 \mathrm{~cm}^{-1}$. At the front end, $1477 \mathrm{~cm}^{-1}$ is the bending vibration peak of $\mathrm{CH}, 1406 \mathrm{~cm}^{-1}$ is the bending vibration peak, $1284 \mathrm{~cm}^{-1}$ is the $\mathrm{CN}$ tensile vibration peak, and $870 \mathrm{~cm}^{-1}$ is the $\mathrm{NH}$ bending vibration peak.

According to the spectrum of oxalic acid, the absorption peaks at $1128 \mathrm{~cm}^{-1}$ and $1259 \mathrm{~cm}^{-1}$ were ascribed to the stretching vibration of $\mathrm{CC}$, the stretching vibration of $\mathrm{CO}$ triggers the absorption peak at $1446 \mathrm{~cm}^{-1}$, the stretching vibration of $\mathrm{CO}$ triggers the peak at $1685 \mathrm{~cm}^{-1}$, and the characteristic peak of the tensile vibration of hydroxyl is at $3429 \mathrm{~cm}^{-1}$. Compared with oxalic acid, the hydroxyl stretching vibration peak in the $\mathrm{ChCl}-\mathrm{O}$ spectrum clearly shifts and forms a broad peak, which indicates the formation of 
intermolecular hydrogen bonds between choline chloride and oxalic acid. In summary, the results indicate the formation of eutectic solvent from choline chloride and oxalic acid.

It can be seen from Figure 6 that the infrared absorption peak position of the DES recovered by vacuum distillation is basically the same as that of the original DES. The absorption peak at $3411 \mathrm{~cm}^{-1}$ corresponds to the stretching vibration of the hydroxyl group in DES, the absorption peak at $1686 \mathrm{~cm}^{-1}$ corresponds to the $\mathrm{CO}$ stretching vibration in okara CNF, and the absorption peak at $1264 \mathrm{~cm}^{-1}$ corresponds to the okara CNF. The tensile vibration of $\mathrm{CN}$ in the okara CNF caused the absorption peak at $783 \mathrm{~cm}^{-1}$ due to the bending deformation vibration of $\mathrm{OH}$ and $\mathrm{CH}$ bonds in CNF. The hydroxyl group at $3411 \mathrm{~cm}^{-1}$ was caused by the humidity of the air during the experiment. The recovered DES solvent showed the characteristic absorption peak resulted from okara CNF.

\subsection{The effect of recycle times on the pretreatment effect}

It can be seen from Fig. 7 that the recovery rate of DES solvent reached $93 \%$ and the yield of okara cellulose was about $25 \%$ for the first three cycles. With the increase of the cycles, the recovery rate of DES dropped from $91 \%$ to $84 \%$ and the corresponding okara cellulose yield dropped from $21.84 \%$ to $19.32 \%$. The decrease in the recovery rate is mainly due to the loss of DES during the rotary evaporation process. Fresh DES should be added to reaction system to compensate for the DES loss after four cycles.

\section{Conclusion}

Through SEM and diameter distribution analysis, it is concluded that preparation of CNF with uniform diameter distribution from okara can be achieved by high-pressure homogenization, ultrasonic and highspeed stirring treatment using deep eutectic solvents. The effect of different mechanical treatments on CNF morphology and diameter distribution were evaluated. The properties of the CNF can be manipulated through the judicial selection of the mechanical treatment process conditions.

High-speed stirring using less energy was proposed as a new method for preparing CNF with uniform diameter distribution. The average diameter of the prepared CNF was $27 \mathrm{~nm}$. DES solvent could be recycled up to three times and the recovery rate reached more than $90 \%$. The yield of okara cellulose was $20.07 \%-24.86 \%$.

\section{Declarations}

\section{Acknowledgements}

This research project was supported by the Key Laboratory Research Open Fund of Shaanxi Provincial Department of Education, Grant No. 17JS017, and the Research Initial Fund of Shaanxi University of Science and Technology, Grant No. BJ15-29.

\section{References}


Benini CDC et al. (2018) Preparation of nanocellulose from Imperata brasiliensis grass using Taguchi method Carbohydrate Polymers Scientific \& Technological Aspects of Industrially Important Polysaccharides.https://doi.org/10.1016/j.carbpol.2018.03.055

Bubalo MC, Curko N, Tomasevic M, Ganic KK, Redovnikovic IR (2016) Green extraction of grape skin phenolics by using deep eutectic solvents Food Chemistry 200:159-

166.https://doi.org/10.1016/j.foodchem.2016.01.040

Chávez-Guerrero L, Vazquez-Rodriguez S, Salinas-Montelongo JA, Roman-Quirino LE, García-Gómez NA (2019) Preparation of all-cellulose composites with optical transparency using the banana pseudostem as a raw material Cellulose.https://doi.org/10.1007/s10570-019-02369-1

llyas RA, Sapuan SM, Sanyang ML, Ishak MR, Zainudin ES (2017) Nanocrystalline Cellulose As Reinforcement For Polymeric Matrix Nanocomposites And Its Potential Applications: A Review Current Analytical Chemistry 264.https://doi.org/10.2174/1573411013666171003155624

Isogai A, Saito T, Fukuzumi H (2011) TEMPO-oxidized cellulose nanofibers Nanoscale 3:7185.https://doi.org/10.1039/CONR00583E

Klemm PD, Kramer F, Moritz S, Lindstr?M T, Ankerfors M, Gray D, Dorris A (2011) Nanocelluloses: a new family of nature-based materials Angew Chem Int Ed 50:5438-

5466.https://doi.org/10.1002/anie.201001273

Li B, Qiao M, Lu F (2012) Composition, Nutrition, and Utilization of Okara (Soybean Residue) Food Reviews International 28:231-252.https://doi.org/10.1080/87559129.2011.595023

Li P, Liu H, Hou Q, Wang Y, Li X (2019) Preparation and Applications of Soybean Residue CNF Films Paper and Biomaterials 004:45-53

Li P, Wang Y, Hou Q, Li X (2018) Isolation and Characterization of Microfibrillated Cellulose from Agroindustrial Soybean Residue (Okara) Bioresources 13.https://doi.org/10.15376/biores.13.4.7944-7956

Li P, Wang Y, Hou Q, Liu H, Li X (2020) Preparation of cellulose nanofibrils from okara by high pressure homogenization method using deep eutectic solvents Cellulose 27.https://doi.org/10.1007/s10570-01902929-5

Liu H, Geng B, Chen Y, Wang H (2016) Review on the Aerogel-Type Oil Sorbents Derived from Nanocellulose ACS Sustainable Chemistry \& Engineering 5.https://doi.org/10.1021/acssuschemeng.6b02301

Mateos-Aparicio I, Mateos-Peinado C, Jiménez-Escrig A, Rupérez P (2010a) Multifunctional antioxidant activity of polysaccharide fractions from the soybean byproduct okara Carbohydrate Polymers 82:245250.https://doi.org/10.1016/j.carbpol.2010.04.020 
Mateos-Aparicio I, Mateos-Peinado C, Rupérez P (2010b) High hydrostatic pressure improves the functionality of dietary fibre in okara by-product from soybean Innovative Food Science \& Emerging Technologies 11:445-450.https://doi.org/10.1016/j.ifset.2010.02.003

Nagano T, Arai Y, Yano H, Aoki T, Nishinari K (2020) Improved physicochemical and functional properties of okara, a soybean residue, by nanocellulose technologies for food development - A review Food Hydrocolloids:105964.https://doi.org/10.1016/j.foodhyd.2020.105964

Nechyporchuk, Oleksandr, Belgacem, Naceur M, Bras, Julien. (2016) Production of cellulose nanofibrils: A review of recent advances Industrial Crops \& Products.https://doi.org/10.1016/j.indcrop.2016.02.016

Nsor-Atindana J, Zhou YX, Saqib MN, Chen M, Zhong F (2019) Enhancing the prebiotic effect of cellulose biopolymer in the gut by physical structuring via particle size manipulation Food Research International:108935.https://doi.org/10.1016/j.foodres.2019.108935

Paiva A, Craveiro R, Aroso I, Martins M, Reis RL, Duarte ARC (2014) Natural Deep Eutectic Solvents Solvents for the 21st Century Acs Sustainable Chemistry \& Engineering 2:10631071.https://doi.org/10.1021/sc500096j

Peiyi et al. (2019) Effect of High Pressure Homogenization Treatment on Structure and Properties of Soybean Residue Cellulose Nanofibers Paper and Biomaterials v.4:40-47

Sirviö JA, Asante B, Liimatainen] H (2018) Recyclable deep eutectic solvent for the production of cationic nanocelluloses Carbohydrate Polymers.https://doi.org/10.1016/j.carbpol.2018.07.024

Stanojevic SP, Barac MB, Pesic MB, Jankovic VS, Vucelic-Radovic BV (2013) Bioactive Proteins and Energy Value of Okara as a Byproduct in Hydrothermal Processing of Soy Milk Journal of Agricultural and Food Chemistry 61.https://doi.org/10.1021/jf4012196

Thomas B et al. (2018) Nanocellulose, a Versatile Green Platform: From Biosources to Materials and Their Applications Chemical Reviews.https://doi.org/10.1021/acs.chemrev.7b00627

Vong WC, Lim XY, Liu SQ (2017) Biotransformation with cellulase, hemicellulase and Yarrowia lipolytica boosts health benefits of okara Appl Microbiol Biotechnol.https://doi.org/10.1007/s00253-017-8431-1

Wang K, Huang S, Ding B, Duan Y, Zhang] J (2019) Ultrafine and carboxylated $\beta$-chitin nanofibers prepared from squid pen and its transparent hydrogels Carbohydrate Polymers.https://doi.org/10.1016/j.carbpol.2019.02.001

\section{Figures}



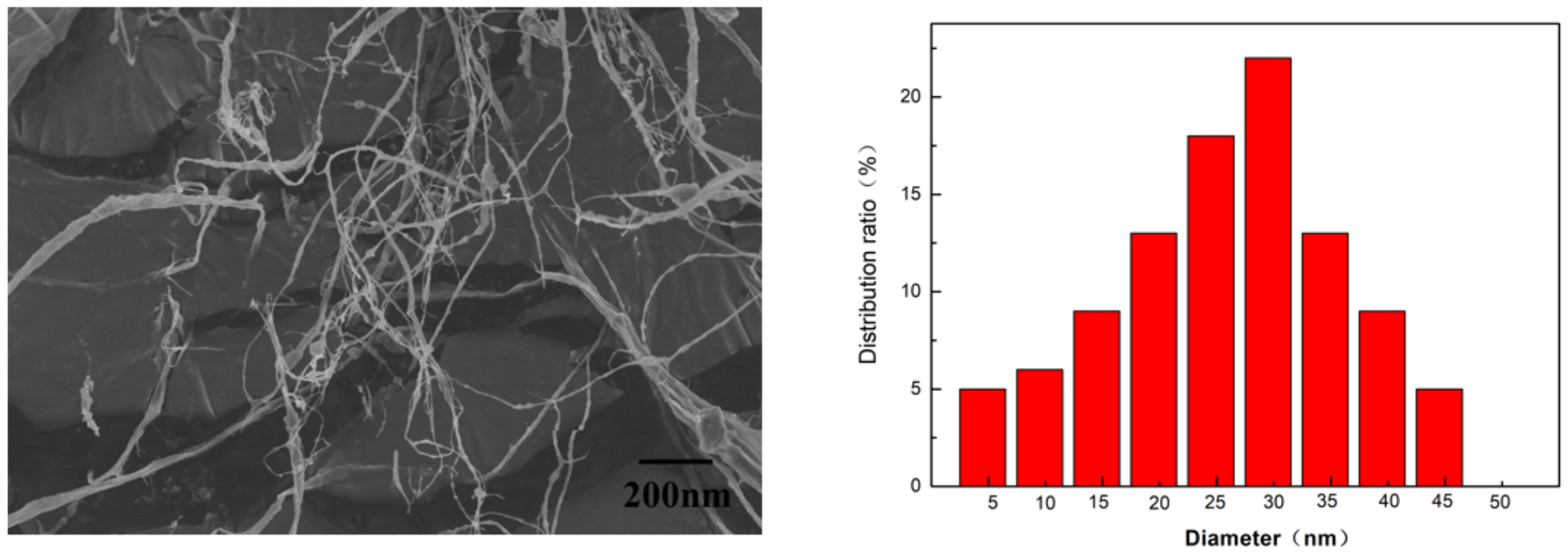

Figure 1

Morphology of CNF prepared by high-pressure homogenization
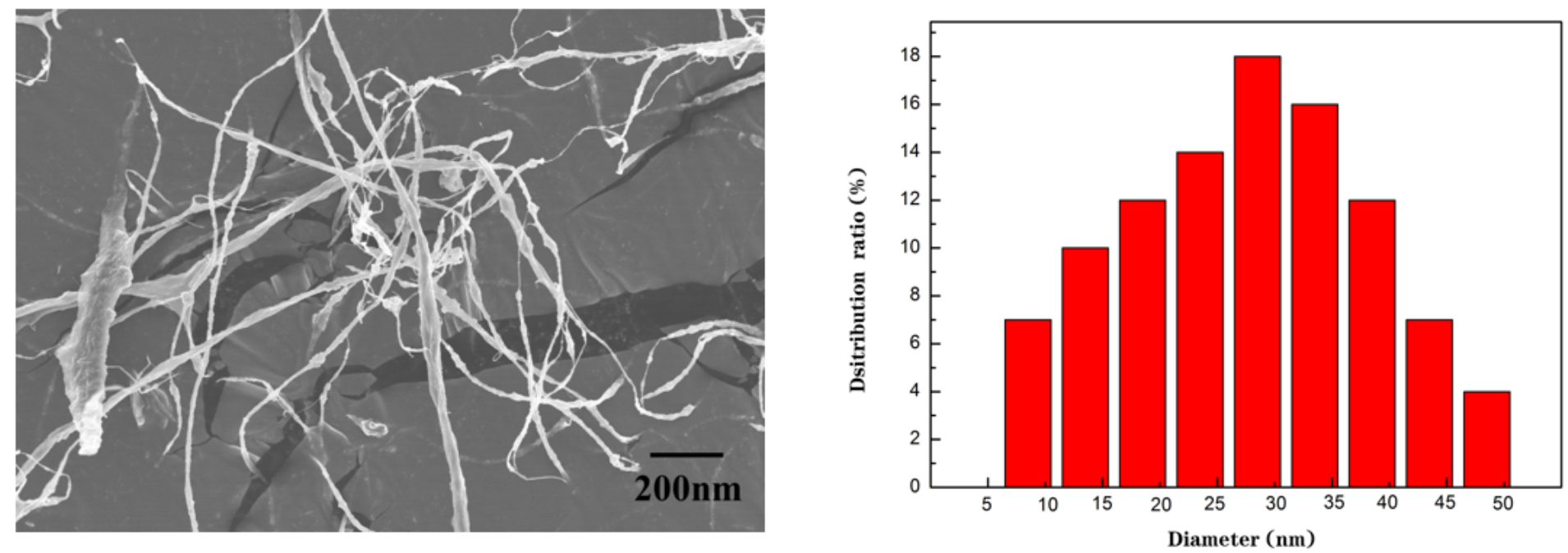

Figure 2

Morphology and diameter distribution of CNF prepared by ultrasonic treatment 

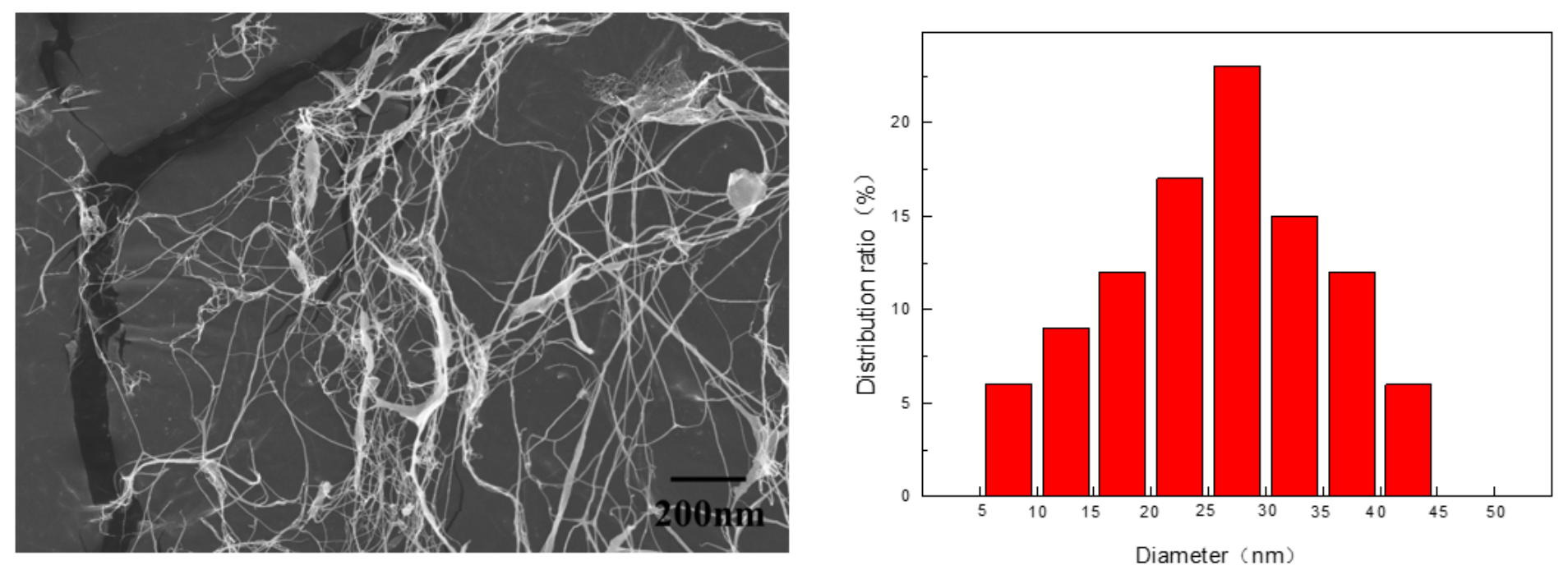

Figure 3

Morphology and diameter of CNF prepared by high-speed stirring

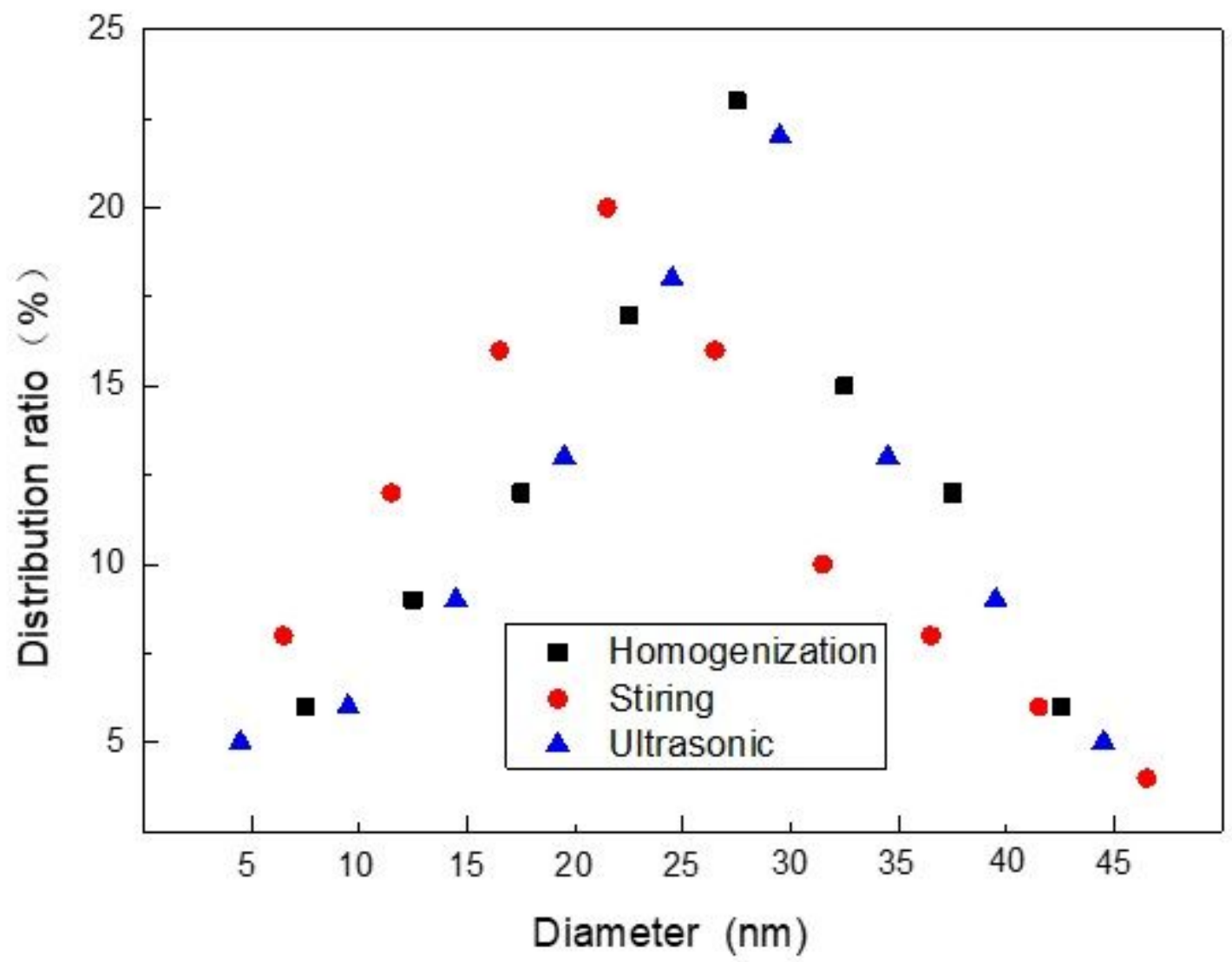

Figure 4

Size distribution of CNF using different mechanical dissociation 


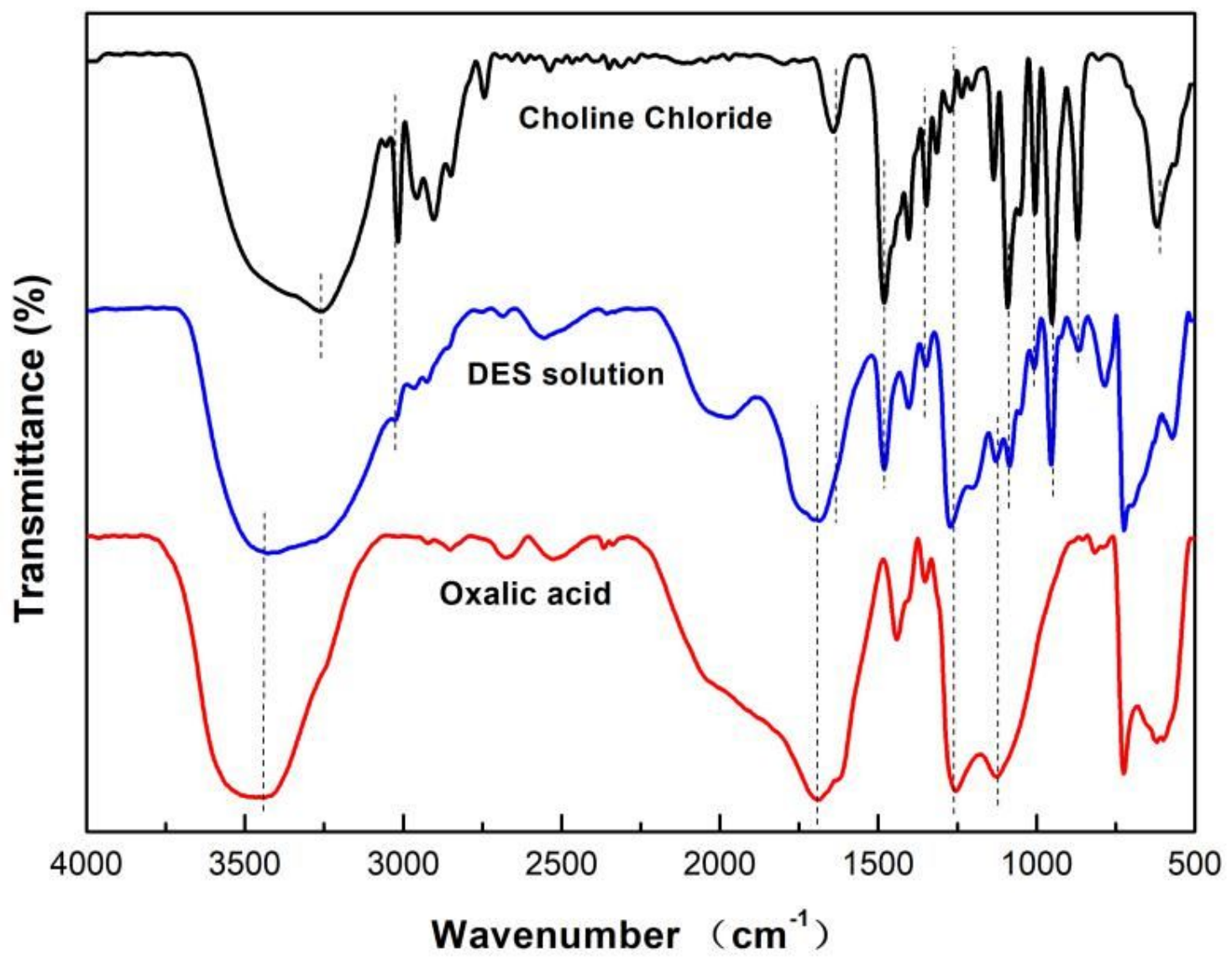

Figure 5

FTIR spectrum of oxalic acid, choline chloride and DES 


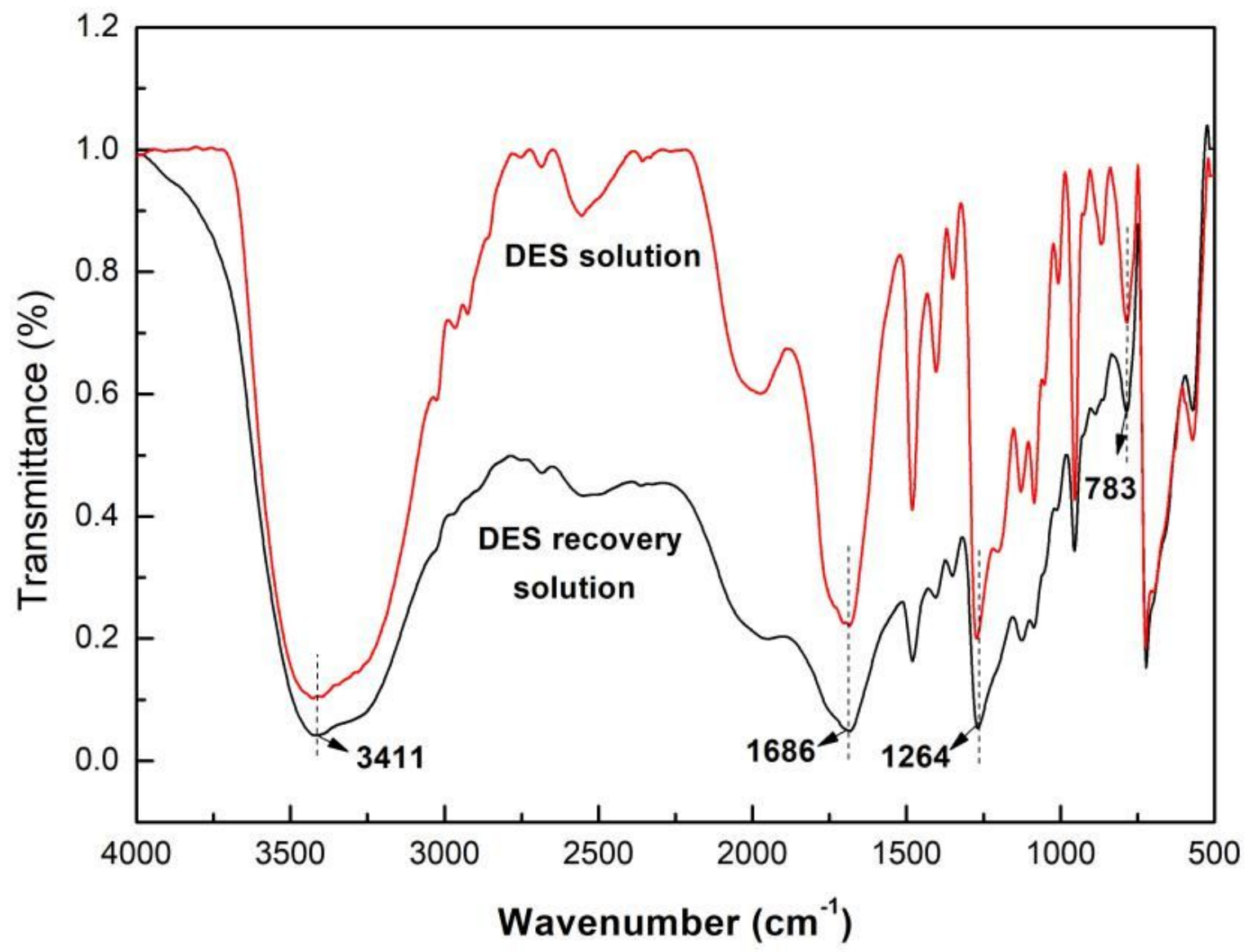

Figure 6

FTIR spectrum of CNF obtained before and after recovery of DES treatment liquid 


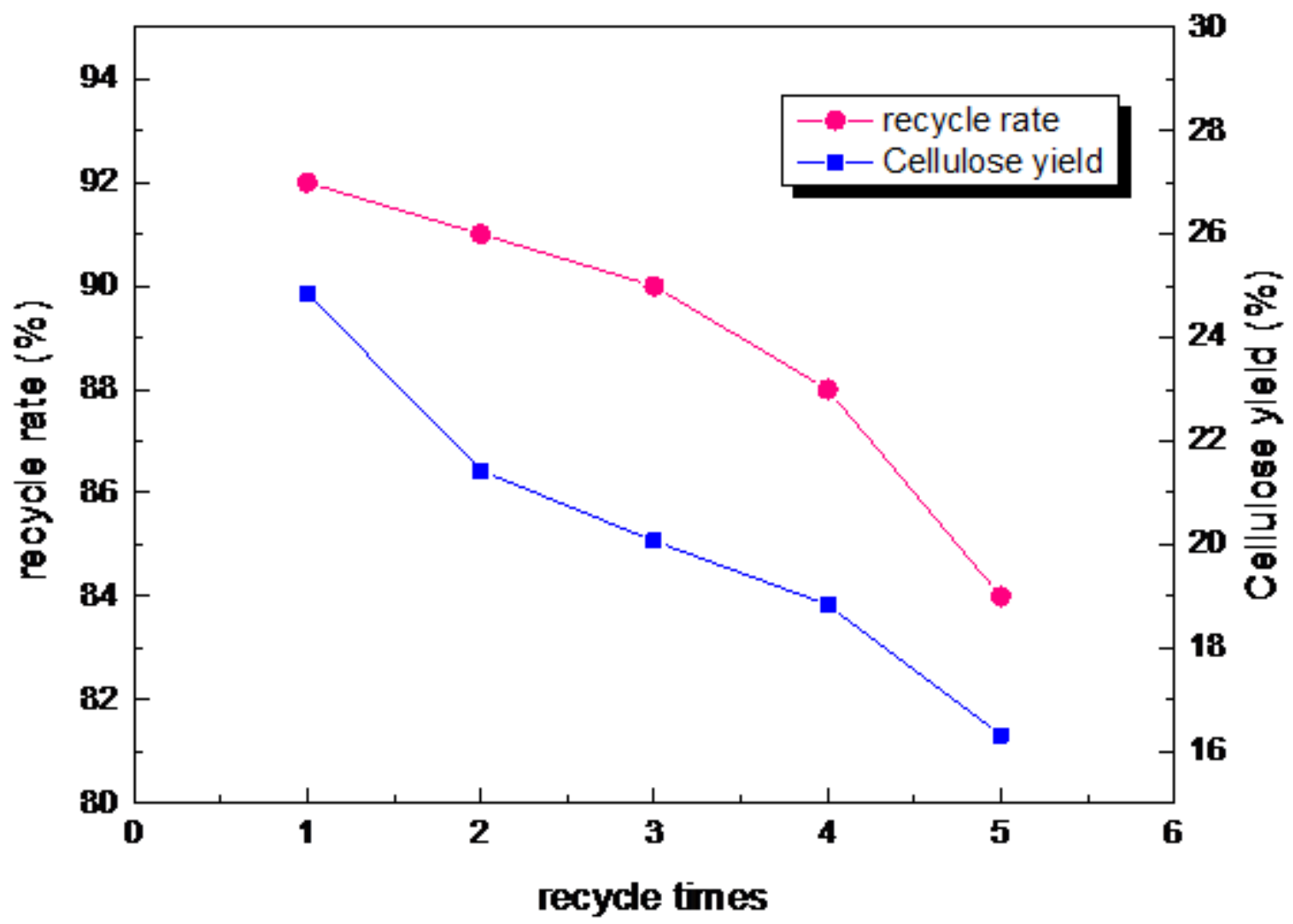

Figure 7

DES recycle rate and cellulose yield

\section{Supplementary Files}

This is a list of supplementary files associated with this preprint. Click to download.

- GraphicalAbstract.jpg 